\title{
LIVRE-ARBITTRIO E PREDESTINAÇÃO DIVINA EM ANSELMO DE CANTUÁRIA
}

Paulo Ricardo Martines*

SÍNTESE - O objetivo deste estudo é apresentar a "famosissima quaestio" que envolve a relação entre a presciência, a predestinação e a graça de Deus com o livre-arbitrio humano, segundo Anselmo de Cantuária. Essa discussão aparece em seu último tratado, De concordia, escrito provavelmente entre 1107-1108. Nesta obra, Anselmo retoma e confirma a definição de liberdade como um poder de conservar a retidäo da vontade, examinando isso à luz da graça divina.

PALAVRAS CHAVE - presciência; predestinação; vontade; livre-arbítrio; liberdade; a obra $D e$ concordia de Anselmo de Cantuária.
ABSTRACT - The aim of this essay is to present the "famosissima quaestio" which embraces the relation between foreknowledge, predestination and the grace of God and human being's free choice according to Anselm of Canterbury. This discussion can be found in Anselm's last treatise, De concordia, written around 1107-1108. In this work, Anselm confirms the definition of freedom as a power to preserve the rectitude of the will, examining this issue on the light of the divine grace.

KEY WORDS - Foreknowledge. Predestination. Will. Free choice. Freedom. Anselm's work De concordia.

O objetivo desta comunicação é apresentar a famosissima quaestio que envolve a relação entre a presciência, a predestinação e a graça de Deus com o livrearbítrio humano, segundo Anselmo de Cantuária. Esta discussão aparece em seu último tratado, De Concordia, escrito provavelmente entre 1107-1108. Nesta obra, Anselmo retoma e confirma a definição de liberdade como um poder de conservar a retidão da vontade, examinando a questão à luz da graça divina ${ }^{1}$.

$O$ De Concordia é um longo tratado dividido em 3 questões: a primeira, diz respeito à presciência divina e o livre-arbítrio; a segunda, a relaçăo entre a predestinação e o livre-arbítrio; a terceira, sobre a graça e o livre-arbítrio. 0 movimento geral da obra procura responder às questões relativas à responsabilidade das açōes humanas: 1) por que a vontade não tem a retidão que deveria ter? 2) de que modo o homem faz o bem pelo livre-arbítrio (sob a conduta da graça) e o mal

* UEM.

1 Utilizamos a edição crítica latina preparada por F.S. Schmitt (S. Anselmi, opera omnia): De concordia praescientiae et praedestinationis et gratiae dei cum libero arbitrio, p. 156-288. Doravante citaremos dessa edição apenas a página e a(s) linha(s), por exemplo, De Concordia, 222: 15.

\begin{tabular}{|l|l|l|l|l|l|}
\hline VERITAS & Porto Alegre & v. 48 & n. 3 & Setembro 2003 & p. 391-396 \\
\hline
\end{tabular}


apenas por obra de sua vontade ${ }^{2}$ Nesta comunicação reteremos apenas a segunda questão, sobre a predestinação e o livre-arbítrio.

A elaboração e a resolução sobre o acordo da predestinação com o livre-arbítrio permitirá, por um lado, reafirmar o poder livre da vontade diante de Deus, e por outro, confirmar o desígnio providencial de Deus, decorrente de sua eterna sabedoria. A questāo sobre a predestinação apresenta uma posição estratégica ${ }^{3}$ no corpo do tratado, pelo fato de relacionar-se diretamente, seja com a primeira questẫo (no tocante ao aspecto da solução dada à dificuldade sobre o termo necessidade), seja com a terceira (pela afirmação do papel preponderante que assume a noção da graça). Que Deus saiba de antemão ou predestine não implica que as açōes humanas pereçam diante desta inevitabilidade. As ações são livres porque Deus as sabe de antemão, e as predestina como tais, porque ele quer que a vontade do homem não seja coagida ou movida por nenhuma necessidade: "necesse est voluntatem esse liberam" (De Concordia, 251: 8-9). De fato, não há incompatibilidade entre presciência e predestinação e o livre-arbítrio. Pode-se confirmar isto tomando como modelo o caso da liberdade humana, enquanto um poder reto da vontade, que coincide, na sua livre submissão, com a vontade de Deus.

Predestinação é uma preordenação ou pré-instituição (praeordinatio ou praestitutio). Quando se afirma que Deus predestina, isso deve ser entendido como uma preordenação, isto é, que ele estabelece (statuit) que algo acontecerá no futuro, e isso de uma forma irrevogável, necessária: "et ideo quod deus praedestinare dicitur, intelligitur praeordinare, quod est statuere futurum esse" (id, 260: 10-12). Isso posto, parecem inconciliáveis a predestinação de Deus e o livre-arbítrio do homem, podendo a dificuldade ser assim formulada: 1) se Deus predestina os bens e os males, nada se faz pelo livre-arbítrio, mas por necessidade; 2) se Deus predestina somente os bens, somente estes são por necessidade, havendo livrearbítrio apenas para os males; 3 ) se o livre-arbítrio faz certas obras boas sem que fossem predestinadas, Deus não predestinaria todas as obras; logo não predestina os justos, indo em sentido contrário aos versículos de Rm 8,29-304; 4) se Deus predestina por necessidade, parece que o livre-arbítrio não é nada. Inicialmente, Anselmo afirma que a predestinação não concerne apenas aos bens que são feitos pela vontade, mas também aos males, sendo que esses últimos podem ser explica-

2 Estas duas questōes apresentam por extenso a seguinte formulação: "cur autem non habeat quam semper debet habere (...) qualiter homo bona faciat per liberum arbitrium praesulante gratia et malum sola sua operante propia voluntate (De Concordia, 259: 23-26). Anselmo apresenta essas duas questões quando considera a injustiça (ausência de retidão) que está na vontade da criatura racional, na qual deveria estar apenas a justiça.

3 Ver a respeito Corbin (nota b de sua tradução L' oeuvre de $S$. Anselme de Canterbery, v. 5, p. 191) e Briancesco (El ultimo Anselmo, p. 68).

4 "Porque os que de antemáo ele conheceu, esses também ele predestinou a serem conformes à imagem de seu filho, a fim de ser ele o primogênito entre muitos irmăos. E os que predestinou, também os chamou, e os que chamou, também justificou, e os que justificou, também os glorificou". Esses versículos da Carta aos Romanos $(8,29)$ já presentes na primeira questão comandam a inteligibilidade sobre a presciência e a predestinação, e anunciam, igualmente, a obra de justificaçăo e glorificaçâo que será indicada na última questâo. 
dos apenas pela vontade permissiva de Deus: "deus mala quae non facit dicitur facere, quia permittit" (id, 261: 4).

A explicação acerca da vontade má apresenta no De Concordia alguns dados novos em relação ao De casu diaboli, sobretudo o uso de um vocabulário de ordem metafísica. A vontade tomada em si mesma (Anselmo emprega o termo essentialiter para descrevê-la) não é nem mais ou menos justa ou injusta. Será preciso distinguir o emprego da essência da vontade (presente tanto nas açōes justas ou injustas) das próprias ações, que podem ser boas ou más. As ações boas, Deus as realiza essencialmente e igualmente boas; as ações más, Deus as realiza apenas essencialmente: "Assim, em todas as vontades e ações boas, Deus as faz ao mesmo tempo que elas sejam essencialmente e que sejam boas; nas más, não as faz que que sejam más, mas somente que as sejam por essência. Assim, como as essências das coisas vêm apenas de Deus, também ela é apenas reta por ele" (id, 259: 17-20). A solução da aparente oposição entre a predestinação de Deus e o livrearbítrio do homem é apresentada em dois momentos.

Num primeiro momento, o acordo é explicitado na idéia de que Deus vê tudo em sua eternidade; para ele não há um antes nem um depois: "omnia sunt illi simul praesentia" (id, 261: 12). Esta referência à eternidade é apresentada com mais detalhes na primeira questão. 0 cap. 5 dessa questão articula as noções de tempo e eternidade relativas ao problema da presciência dos eventos futuros e de sua conseqüente necessidade, segundo uma forma canônica: aquilo que é conhecido de antemão e se realiza segundo o livre-arbítrio deve ser compreendido segundo a eternidade, e não segundo o tempo, no qual as ações podem ou não ocorrer. Para Anselmo, isso é declarado pela Sagrada Escritura: "Tudo o que se faz pelo livrearbítrio, diz a Sagrada Escritura necessariamente, se faz segundo a eternidade, de onde todo verdadeiro, e nada mais que o verdadeiro é imutavelmente presente, não segundo o tempo, no qual nem sempre estão nossas vontades e ações, pois como não é necessário que sejam, enquanto não são, também, não é freqüentemente necessário que por vezes sejam" (254: 27-8; 255: 1-4). Apenas segundo o tempo reconhecemos aquilo que se apresenta dentro de uma seqüência, ou seja, constatamos aquilo que foi, é e será. Por sua vez, dizer segundo a eternidade é reconhecer a idéia de simultaneidade ${ }^{5}$.

Da mesma forma que Deus tem a presciência dos eventos futuros, ele também os predestina, e isso sem apresentar nenhuma inconveniência com o livre-arbítrio. 0 mesmo vale ainda para a conexäo entre justiça e liberdade, na medida em que as ações justas são praticadas sem qualquer traço de necessidade, ainda que sejam conhecidas de antemão e predestinadas por Deus, pois a justiça somente pode ser conservada por uma vontade livre: "Com efeito, Deus não conhece de antemão

5 A esse respeito vale relembrar o exemplo de Boécio retomado por Tomás de Aquino: daquele que marcha sobre um caminho e nâo vê os que o seguem, enquanto que aquele que está localizado numa certa altura vê simultaneamente todos aqueles que marcham sobre esse caminho. (Summa theologiae $\mathrm{I}^{\mathrm{a}}$, Q. $14^{\mathrm{a}}, 13$, ad. 3). Cf. Boécio, Philosophiae consolatio, livro V, prosa 6. 
nem predestina algo justo como futuro por necessidade. Com efeito, não tem a justiça que não a conserva por uma vontade livre" (id, 261: 20-22).

Num segundo momento, a solução da aparente oposição entre predestinação e livre-arbítrio é formulada a partir da compreensão do termo necessidade, já que os movimentos do livre-arbítrio apresentam, enquanto previstos e predestinados por Deus, uma necessidade futura. Sendo assim, Anselmo é levado a considerar com mais atenção este termo. Aquilo que é predestinado não ocorre pela necessidade que precede e faz a coisa, mas por aquela que segue a coisa: "non eveniunt ea necessitate quae praecedit rem et facit, sed ea quae rem sequitur" (id, 262: 2). Vejamos o sentido e o alcance do conceito de necessidade para Anselmo.

A palavra necessidade parece invocar qualquer tipo de coação ou proibição (coactio vel prohibitio), por exemplo, quando se afirma que algo coibiu ou forçou determinada vontade ou desejo de se manifestar. É o que se observa no discurso daqueles que procuram identificar uma certa inevitabilidade em determinadas ações, nas quais não se vê outra coisa senão uma determinação livre da vontade ${ }^{6}$. Mas, observa Anselmo, quando se afirma que é necessário que Deus seja imortal ou que não seja injusto, não se deve entender que alguma força o constranja a ser imortal ou que haja uma proibição de ele ser injusto, mas apenas que nada pode fazer o contrário daquilo que ele é: "nulla res potest facere, ut non sit immortalis aut sit iniustus" (id, 247: 10-11). O seu ponto de partida é a afirmação de que é necessário que algo seja futuro sem necessidade.

Se Deus tem a presciência de algo, é necessário que este algo seja no futuro: "si erit, ex necessitate erit", e tal necessidade é aquela que segue a posição da coisa. Antes de tudo, o que deve ser destacado nesta formulação de Anselmo é o papel central que assume a noção de res, que é igualmente importante em outros momentos de sua obra e possui um conteúdo claramente ontológico, como vemos nesta passagem, do Cur Deus Homo: "sed esse rei facit necessitatem esse" (17: 125-7). Uma vez a coisa "estabelecida", ela o é por necessidade: "ponitur res esse, dicitur ex necessitate esse" (De Concordia, 249: 3-5); caso não seja estabelecida, ela não o é por necessiadade: "ponitur non esse, affirmatur non esse ex necessitate" (id). Anselmo tem em mente a distinção: 1) dizer que uma coisa é futura (o que não implica a necessidade de que ela ocorra) e 2) dizer que uma coisa futura é futura (o que implica uma necessidade, pois ela não pode não ser) ${ }^{7}$. Considerando este último aspecto, pode-se dizer que aquilo que Deus sabe de antemão como fu-

6 Contra aqueles que defendem teses que podem apresentar algum tipo de orientação determinista, Anselmo se vale de um exemplo simples e suficientemente claro: alguém que mata uma pessoa pelo fato de esta ter-lhe feito uma série de injúrias. É por obra espontânea da vontade que um deles quis ofender e o outro quis matar, ainda que cada um tenha sua razão particular. Não se pode dizer, conclui Anselmo, que tal ato se efetivou porque Deus sabia de antemão ou o tenha predestinado como tal. Ambos agiram apenas por suas vontades (sola voluntate). Cf. De Concordia, 262: 13-22.

7 Para o primeiro caso, Anselmo sugere um exemplo padrão: amanhã haverá uma revolta na cidade, que pode ou nảo acontecer (De Concordia, 250: 14). Para o segundo caso, o exemplo proposto é aquele do movimento necessário do céu: "cum dicitur caelum volvi, quia necesse est ut volvatur" (Cur deus homo, 17, 125: 9-10). 
turo, é necessário que seja futuro, pois o futuro não pode ser ao mesmo tempo no futuro.

Quando Anselmo considerou pela primeira vez a noção de necessidade - no Cur deus homo, pôde constatar que o tratamento que a questão recebeu foi exatamente o mesmo: é afirmado o duplo sentido do termo, sendo que a necessidade que segue não coage em nada o acontecimento de algo. $O$ mestre de Bec cita nominalmente Aristóteles, ao referir-se à questão das proposições singulares futuras, presentes no De interpretatione, $I X^{8}$. 0 dado novo diz respeito à necessidade implicada na vontade divina do filho de Deus: ao dizer que ele não podia querer não morrer, não se deve entender que não poderia conservar a sua vida imortal, mas que esse ato concerne somente à imutabilidade de sua vontade, pela qual ele se fez homem a fim de morrer para salvar a humanidade.

De fato, Anselmo procura preservar a completa liberdade da vontade diante da presciência e predestinação de Deus, o que fora apenas possível conciliando, no ato livre, a espontaneidade (sponte) que lhe é inerente (fruto do liberum arbitrium) e a necessidade, porque ele é um futurum na ciência eterna de Deus. Um traço de fundamental importância confirma o propósito de Anselmo de não contrapor a liberdade da criatura humana à predestinação de Deus, pois, a liberdade é afirmada a partir da reta ordenação divina: Deus não coage a vontade ou se opõe a ela, mas remete para ela o seu próprio poder: "non enim ea deus - quamvis paedestinet - facit voluntatem cogendo aut voluntati resistendo, sed in sua illam potestate dimittendo" (262: 3-4). Devemos entender in potestate dimittere como um dom gracioso que a criatura racional recebe ao mesmo tempo a dignifica como ser criado, e deve também ser conservado pelo amor dele próprio. Anselmo acrescenta na passagem imediatamente seguinte que o próprio uso desta vontade, quando concernente às boas ações, refere-se à graça de Deus, sendo que as más ações não têm como origem outra coisa senão a própria vontade: "quamvis tamen sua voluntas utattur potestate, nihil tamen facit, quod deus non faciat in bonis sua gratia, in malis non sua sed eiusdem voluntatis culpa" (262: 4-6).

\section{Referências}

S. Anselmi - Opera omnia (2 v.). Stuttgart: Bad Cannstatt, 1984.

$L$ 'oeuvre d'Anselme de Canterbery. Sous la direction de Michel Corbin. Paris: Les Éditions du Cerf, 1986-1994.

Anselmo d'Aosta. Libertà e arbitrio. A cura de I. Sciuto. Firenze: Nardini, 1992.

BRIANCESCO, E. El ultimo Anselmo. In: Patristica et Medievalia, n. 8, p. 63-89, 1987.

8 Anselmo teve acesso a esta discussāo pelo próprio texto de Aristóteles e pelo comentário de Boécio ao Peri hermeneias. Neste, Boécio descreve a dupla necessidade segundo os termos simples e condicional: "duabus his necessitatibus demonstrati, uma condicionali, altera simplici, nunc ad contradictionem rursus de futuro contingenque revertitur", citado por H.R. Patch, Necessity in Boethius and the neoplatonistis, in Speculum X, p. 395-410. Segundo Courcelle (La consolation de la philosophie dans la tradition littéraire: antécedents et postérité de Boèce. Paris: Études augustiniennes, 1956) a formulação e resolução de Boécio têm como fonte o comentánio de Amônio ao De interpretatione. 
CANTIN, A. Foi et dialectique au XI siècle. Paris: Les Éditions du Cerf, 1997.

CORBIN, M. Necessité et liberté. Sens et structure de l' argument du Cur deus homo. In: Humanisme et foi chrétienne. 1977. p. 599-632.

Prière et raison de la foi. Introduction à l' oeuvre de saint Anselme. Paris: Les Éditons du Cerf, 1997.

CORVINO, F. Necessità e libertà di Dio in Píer Daminani e in Anselmo d' Aosta. In: Analecta Anselmiana, n. 5, p. 245-260, 1976.

EVANS, G.R. Anselme and talking about God. Oxford: Clarendon Press, 1978.

GRAIG, W.L. St. Anselmon divine foreknowledge and future contingency. In: Laval Théologique et Philosophique, n. 42, p. 93-104, 1986.

HOPKINS, J. A companion to the study of St. Anselm. Minneapolis: University of Minnessota Press, 1972. 